\title{
CYTOLOGICAL STUDIES ON THE PERFFET \\ STAGES OF SOME SPECIES OF FUSARIUM
}

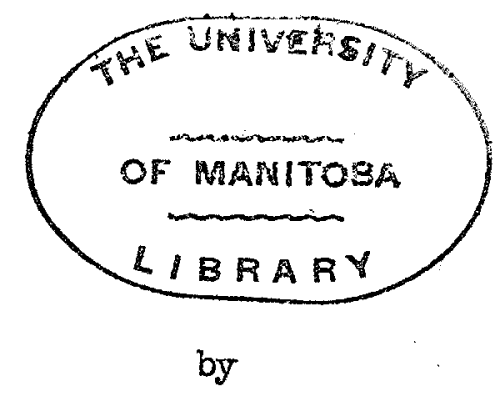

William Thompson Howson

\author{
A Thesis \\ Submitted to \\ The Faculty of Graduate Studies and Research \\ University of Manitoba \\ in Partial Fulfilment of the \\ Degree Master of Science
}

April, 1962 
CYTOLOGICAL STUDIES ON THE PERFECT STAGES OF SOME SPECIES OF FUSARIUM

by W. T. Howson

\section{Abstract}

The main purpose of this investigation was to study the chromosomes with regard to number and morphology of some Fusarium species. This was found to be possible when the fungus is in the sexual cycle or what is called the perfect stage. The procedure followed for studying the chromosomes was to squeeze the asci out of the perithecium, mount them on a slide and stain them. A wide variety of fixatives and stains were investigated during the early stages of this work and it was found that fixation in Carnoy's solution followed by staining with aceto-orcein or aceto-carmine was the most satisfactory.

The chromosome number of seven different species has been determined. In both the homothallic and the heterothallic strains of Hypomyces solani five pairs were found whereas four pairs were found in Gibberella zeae, G. cyanogena, G. cyanea, G. stilboides and G. fujikuroi, and seven pairs were found in Calonectria nivalis. The number of chromosomes in the latter four species had not been reported previously.

In Gibberella cyanogena, examined at mitotic metaphase in the ascus, there appeared to be one short, two intermediate and one long chromosome with a length ratio of $1.0: 1.2: 1.5: 1.7$. No association between homo- and heterothallism and chromosome number was found. 


\section{ACKNONLEDGNENTS}

Grateful acknowledgment is given to Dr. W. I. Gordon, Canada Department of Agriculture, Research Station, Winnipeg, for supplying the materials, making the necessary crosses and for his guidance in this study; to Dr. R. C. McGinnis, Department of Plant Science, The University of Manitoba for assistance and guidance throughout this study, and his help in preparing the manuscript; to irr. D. Fox of The University of Ianitoba for the photographic plates; and to the National Research Council of Canada for financial assistance in the form of a Bursary. 
TABLE OF CONTENTS

PAGE

INTRODUCTION .................... I

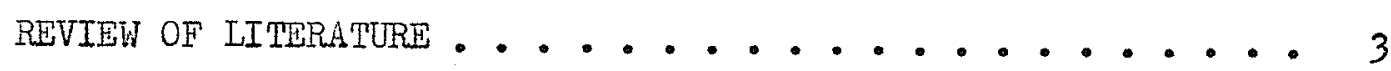

HYPONYCES SOLANI RK. \& Berth. emend,S. \& H. . . . . . 3

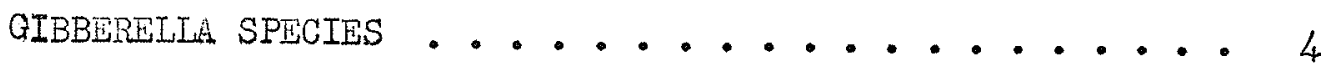

CALONECTRIA RIGIDIUSCULA (Berk. \& Br.) Sacc. ...... 4

RELATIONSHIP BETWEEN CHRONOSOME NUMBER AND

SEXUAL BEHAVIOUR . . . . . . . . . . . . . . 4

CYTOLOGICAL TPEHNIQUES . . . . . . . . . . . 5

MATERIALS AITD METHODS .................. 6

SPECIES .......................... 6

CULTURING . . . . . . . . . . . . . . . 7

PRETREATMENTS OF FIXING MATERIAI . . . . . . . . . 7

STAINING TECHNIQUES ................ 7

1. Giemsa stain ............. 8

2. Propiono-carmine stain ........... 9

3. Feulgen's stain..................... 10

4. Aceto-orcein stain ............. 10

5. Aceto-carmine stain ............ 11

TECHNTQUE FOR MAKING SLIDES PERMANENT .......... II

OBSERVATIONS AND PHOTOGRAPHS ............ 12

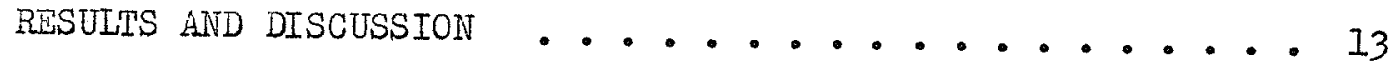

STAINING TECHNIQUES ............... 13 
CYTOLOGY OF SPECIES .............. 15

Hypomyces solani Rke. \& Berth. emend. S. \& H. .... 15 (= Fusarium solani (Mart.) App. \& W. emend.S. \& H.)

Calonectria nivalis Schaffnit . . . . . . . 16 (= Fusarium nivale $(F r$.$) Ces.)$

Gibberella zeae (Schw.) Petch .......... 17 (= Fusarium graminearum Schwabe)

Gibberella stilboides Gordon .......... I7 (= Fusarium stilboides Wr.)

Gibberella fujikuroi (Saw.) Wr. ........ 18 (= Fusarium moniliforme Sheld.)

Gibberella cyanea (Sollm.) Wr. ......... 18 (= Fusarium heterosporum Nees)

Gibberella cyanogena (Desm.) Sacc. . . . . . . 19 (= Fusarium sambucinum Fuckel $1.6 \mathrm{Wr}$.)

GERERAI DISCUSSION ...................... 31

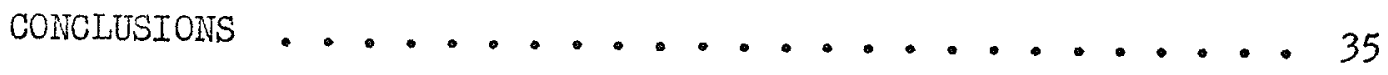

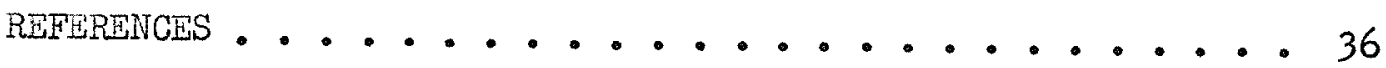




\section{INTRODUCTION}

The examination of chromosomes is of fundamental significance in the study of any organism as it is related directly to inheritance by the elucidation of linkage groups and to taxonomic classification by the revelation of phylogenetic affinity. Furthermore, sexuality is often directly related to the number and norphology of the chromosomes present.

The study of fungal chromosomes has been hampered by their minute size with the result that relevant information is fragmentory and often contradictory. Karyotypic analyses are especially laborious and havebeen attempted rarely. The chromosomes of the asezual stage of fungi are very reduced in size precluding accurate study. In fact, it is still uncertain whether fungi follow the classical pattern of nuclear division in the asexual stage. However, when a fungus enters the sexual stage the chromosomes enlarge sufficiently to permit much more detailed observation.

The widespread occurrence of fungi in the as exual stage has necessitated the development of a taxonomic system based entirely on this stage in addition to the usual, less artificiel, classification based primarily on sexual characters in which phylogenetic relationships are more clearly revealed. As a consequence fungi with both stages are classified in two different taxonomic systems.

The purpose of the present investigation was to determine the number and morphology of the chromosomes of various perfect genera of 
fungi (Hypomyces, Gibberella and Calonectria) whose asexual stages are included in the form-genus Fusarium. The cytological divergence of fungi whose asexual stages are similar could thus be determined. Moreover, the number of species available for investigation in the genus Gibberella could provide some opportunity for discovering a polyploid series, should one exist. The phenomenon of homo- and heterothallism and its relationship to chromosome number could be investigated in Hypomyces solani in which both strains are present. 


\section{REVIEW OF LITERATURE}

Relatively few studies have dealt with the cytology of Fusarium species. For clarity in presentation each genus will be dealt with separately.

\section{HYPOMYCES SOLANI}

A pathogenic strain of this species designated fo cucurbitae S. \& $\mathrm{H}_{0}$, which normally is heterothallic has been most intensively studied. The basis of the different sex types in this strain (hermaphrodites, males, females, and neuters) was proposed by Hansen and snyder (7) to be due to two loci each independentily determining one of the sexes. Hirsch (8) concluded from her cytological observations that the sex types were determined by different chromosome numbers, the hermaphrodites having $n=4$, the males and females $n=3$ and the neuters $n=2$.

El Ani (2) inferred from genetical data that Hirsch's conclusions were unlikely and in the same year (3) his cytological investigation at various stages of ascal development of a female $X$ male cross showed four haploid chromosomes consistently. Further work by the same author (4) confirmed these results.

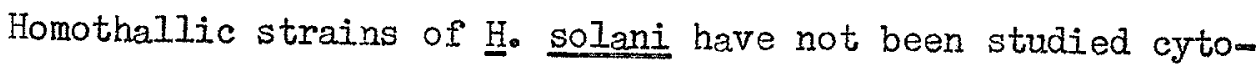
logically to the same extent as heterothallic strains. The earliest report of the chromosome number in the homothallic strains was made by Hirsch (8) who concluded that there were six haploid chromosomes. In a later report, however, El Ani (6) suggested that there were $n=5$ 
chromosomes in this strain.

GIBBERELLA SPECIES

The chromosome numbers of a few species of Gibberella have been reported but some of the conclusions reached are contradictory. In a study by Hirsch et al. (9) the haploid number of chromosomes in G. * lateritium (Neesemend, S. \& H.) and in G. roseum (Ik.) S. \& H. was determined to be $n=6$. Gordon (personal communication) found $n=4$ in G. zeae and in G. cyanogena. A later paper by EI Ani (4) also states that $\mathrm{G}$. cyanogena has $\mathrm{n}=4$. This species is grouped taxonomically under G. roseum by Snyder and Hansen (16) as are $\underline{G}$. cyanea and G. zeae. G. Stilboides would be considered a synonym of G. lateritium.

CAIONECTRIA RIGIDIUSCULA (Berk. \& Br.) Sacc.

Calonectria rigidiuscula was reported by Hirsch et al (9) as having $n=7$. However, her photographic evidence is inconclusive. The closely related species Calonectria nivalis has not been investigated cytologically prior to the present study.

RELATIONSHIP BETWEEN CHROMOSONE NUNBER AND SEXUAL BEHAVIOUR

Sexual behaviour in fungi is determined by two components, sexual differentiation and physiological compatibility. Olive (13), in 1953, summarized our knowledge of the compatibility types in fungi and more recently an extensive review of this topic was given by Raper $\left(I_{4}\right)$. Hansen and Snyder (7) showed that in $\mathrm{H}_{\text {. Solani morpho- }}$ 
logical sexual differentiation and physiological compatibility were distinct and independent phenomena. McGinnis (12) on the basis of his work on species of Puccinia, hypothesized that homo- and heterothallism may be associated with chromosome number. A similar conclusion can be inferred from the work of $\mathrm{El}$ Ani $(4,6)$ who stated that the homothallic strain of Hypomyces solani had $n=5$ chromosomes whereas the heterothallic strains had $n=40$

\section{CYTOLOGICAI TECHNIQUES}

For the cytological study of fungi the aceto-carmine and acetoorcein squash techniques have been used most commonly $(6,11,15)$. However, Hruschovetz (10) reported using Giemsa stain successfully in another Ascomycete (Cochliobolus) whereas Iu (personal communication) has found propiono-carmine to give satisfactory results on Neurospora crassa Shear and Dodge. 
MATERIALS AND METHODS

\section{SPECIES}

The material used in the present study was supplied by Dr. Gordon (Gan. Dept. of Agric. Research Station, Winnipeg, Man.) and consisted of the seven following species:

Hyoomyces solani Rke. and Berth. emend. S. \& H. (homothallic and heterothallic strains),

Gibberella cyanea (Sollm.) Wr.,

Gibberella cyanogena (Desm.) Sacc.,

Gibberella zeae (Schw.) Petch,

Gibberella stilboides Gordon,

Gibberella fujikuroi (Saw.) Wr.,

Calonectria nivalis Schaffnit

All the genera studied belong to the family Hypocreaceae; the distinction between them being based on only a few characteristics. A simplified taxonomic key (Gordon, personal communication) is given as follows:

Perithecia red or yellow Ascospores 1-septate ................ Hypomyces Perithecia bright coloured, pale, wax-coloured to brown.

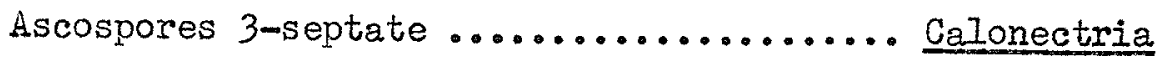

Perithecia blue or violet

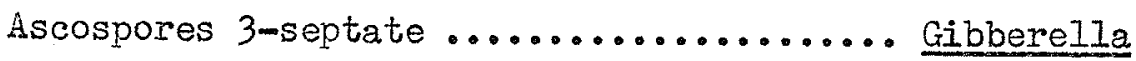

The genus Gibberella has been subjected to some revision by Snyder and 
Hansen (16); however the older classification of species in this genus by Wollenweber and Reinking (18) has been followed in this study.

CULTURING

All culturing was done in medicine bottles on sterilized wheat straw in sterile water. The environment was uniform having a constant light intensity and a controlled temperature of about $60^{\circ} \mathrm{F}$. and under these conditions the perithecia usually developed on the straw several weeks after inoculation. The perithecia from each culture were fixed by transferring the whole straws to a test-tube of fixative and subsequently stored in a refrigerator.

\section{PRETREATMENT OF FIXING MA TERIAL}

Only one type of pretreatment was attempted. This was to chill the perithecia in ice water for 24 hours before fixing, a method which is followed routinely in plant root-tip chromosome studies (17). The purpose of this was to increase the frequency of metaphase configurations in order to facilitate counting the chromosomes.

\section{STAINING TECHNIQUES}

A number of different staining techniques were evaluated critically to determine which would prove most satisfactory in general. It was hoped that a relatively short and simple method could be used for routine cytology to expedite the study. 


\section{Giemsa stain.}

The fixative used for Giemsa stain consisted of 6 parts absolute ethyl alcohol: I part glacial acetic acid: 1 part lactic acid. After 10 minutes immersion in this solution the perithecia were rinsed in $95 \%$ ethyl alcohol and stored in $70 \%$ ethyl alcohol.

Prior hydrolysis is necessary for Giemsa staining. The perithecia were cleaned with dissecting needles under medium power of a dissecting microscope and were placed in cold NHCl for 10 minutes; hydrolyzed in $3 \mathrm{~N} \mathrm{HCl}$ at $60^{\circ} \mathrm{C}$ for 7 minutes, washed in distilled water and placed in phosphate buffer ( $\mathrm{pH}$ 6.9) following the method of Hruschovetz (10). The contents of the perithecia were squeezed out with dissecting needles and placed in fresh buffer in a small vial. An equal portion of Giemsa stain (British Drug Houses) was added to the buffer and the material was left overnight in the staining solution (which was stoppered to prevent evaporation). The stained perithecial contents were placed on a culture slide and removed in small amounts to a drop of buffer (to remove the coagulated stain) on a microscope slide.

Since this method proved to be inadequate, a wide variation in hydrolysis and staining time was employed in different combinations varying from 1 to 15 minutes hydrolysis (in $60^{\circ} \mathrm{C} \mathrm{N} \mathrm{HCl}$ ) and staining time up to several days.

Because the hydrolysis weakened the perithecial walls to the extent that they crumbled upon manipulation (thus contaminating the asci with debris), a variation in technique was attempted whereby the 
asci were squeezed directly into a few drops of hydrolyzing solution on a slide and heated for varying times (within the range described) in a warming oven. The acid was washed off with a few drops of distilled water and finally with buffer. To this an equal amount of Giemsa stain was added and the slide stored in a closed petri dish the bottom of which was lined with a layer of paper soaked in a solution of equal amounts of phosphate buffer and ethyl alcohol to prevent excessive evaporation of the staining solution. A cover glass was then applied with one edge elevated on a razor blade. This reduced the tendency for air bubbles to be trapped underneath and also made possible further separation of the asci by gently tapping the cover-glass with a rubber-tipped pencil. The slide was heated repeatedly over an alcohol lamp and firmly pressed between two layers of paper towels. If microscopic examination was delayed the edges of the coverglass were sealed with wax. This technique was used with all the stains used in this study.

\section{Propiono-carmine stain}

The fixative for this stain consisted of 3 parts n-butyl alcohol: 2 parts glacial acetic acid: 1 part 10\% chromic acid. Hydrolysis was achieved by extruding the asci from a previously cleaned perithecium directly on to a slide in a few drops of a hydrolyzing solution consisting of $I$ part $95 \%$ ethyl alcohol: $I$ part $\mathrm{N} \mathrm{HCl}$. The perithecial walls were removed and the hydrolysis accelerated by heating the slide repeatedly over a burner for about 2 minutes, 
after which the asci were washed in Singleton's solution (6 parts 95\% ethyl alcohol: I part glacial acetic acid: I part lactic acid). In attempts to find a satisfactory degree of hydrolysis, the hydrolyzing time was varied from 0 up to 10 minutes. The stain which consisted of $1 / 2$ gram carmine in $100 \mathrm{ml}$ of $60 \%$ propionic acid was then applied and the coverglass applied as described previously.

\section{Feulgen's stain}

The fixative used for this stain was Carnoy's 6: 3: 1 (6 ethyl alcohol: 3 chloroform: 1 glacial acetic acid). The asci from previously cleaned perithecia were squeezed onto a slide and hydrolyzed in $\mathrm{N} \mathrm{HCl}$ at $60^{\circ} \mathrm{C}$ for various times ranging from one-half to 10 minutes followed by staining in leuco-basic fuchsin for various times up to 12 hours.

\section{Aceto-orcein stain}

No prior hydrolysis was necessary with this stain. The cleaned perithecia which had been fixed with Carnoys 6:3:1 was placed in a drop of stain on the microscope slide, the asci squeezed out and the wall debris removed. If the asci clumped, as they frequently did, separation was accomplished with dissecting needles after which a cover glass was applied. This stain consisted of $2 \%$ synthetic orcein in $60 \%$ acetic acid. Filtering every three days was necessary to remove the precipitates which formed spontaneously. 


\section{Aceto-carmine stain}

The technique is identical to that for aceto-orcein except that filtering of the stain is not periodically required. The aceto-carmine consisted of $1 / 2$ gram of carmine in $100 \mathrm{ml}$ of $45 \%$ acitic acid; a small amount of iron acetate was added to intensify the staining reaction.

TECHIIQUE FOR MAKING SLIDES PERMANENT

The slides were made permanent by a modification of the $\mathrm{CO}_{2}$ quick-freezing method, described by Conger and Fairchild (1). Prior to freezing any sealing wax around the coverglass had to be removed. The slide with the coverslip on the upper side was positioned in the holder and the gas turned on. Freezing was continued until the underside of the slide was white at which time the coverslip could be flicked off with a razor blade. The slide was then immersed I-2 minutes into $95 \%$ ethyl alcohol then I-2 minutes in tertiary butyl alcohol. A d rop of Canada balsam was then placed on the naked specimen and a clean cover slip put into place. This cover slip was centered in the same position as the original by inverting the slide on a paper towel and manouvering the slide until the cover slip fitted the stain outline of the original. The slide was then pressed firmly and stored for at least a week in order to allow the mounting medium to set sufficiently to prevent the cover slip from shifting position when handled. 


\section{OBSERVATIONS AND PHOTOGRAPHS}

Detailed brightfield observations were made at $1125 \mathrm{X}$ with a Leitz "Dialux" microscope fitted with a $90 \mathrm{~K}$ objective having N.A. = 1.32 and an oil immersion condenser, N. A. $=1.40$. Photomicrographs were made at about $1300 \mathrm{X}$ on Kodak Contrast Process Panchromatic film using the Leitz Aristophot microscope camera.

To increase contrast in faintly stained specimens a Zeiss Standard phase contrast microscope with a $100 \mathrm{X}$ oil immersion objective having N.A. $=I_{.} 30$ was used. Photomicrographs using phase contrast were made on the Aristophot camera using the above film. 


\section{RESULTS AND DISCUSSION}

\section{STAINING TECHNIQUES}

Giemsa stain was first used on G. eyanogena with unsatisfactory results and because of the number of perithecia destroyed in investigating a variety of hydrolysis and staining times, it was not used on the other species. The major criticism of the Giemsa stain per se was the lack of differential staining of the cytoplasm and nuclear material. Moreover both of the two hydrolyzing techniques used were unsatisfactory. When the whole perithecium was hydrolyzed the perithecial wall was weakened to such an extent that it crumbled upon further manipulation and when the asci alone were hydrolyzed a large fraction of them was lost.

The propiono-carmine technique was not found to be satisfactory per se due to the very weak staining reaction. The hydroIysis had the same disadvantages that applied to the Giemsa staining method. The direct staining of the asci with propiono-carmine (i.e. without hydrolysis) was found to have some value. In the latter case the immediate staining was extremely faint but after the slides had been stored for several weeks (without being made permanent) it deepened considerably. The image was further improved by using phase contrast for observation. One of the advantages of the use of carmine (either with propionic or acetic acid) was that it stained the nucleolus well; this was not the case for any of the other stains investigated. 
The use of Feulgen staining was investigated in a limited way. Since hydrolysis is essential the previously mentioned criticisms of this procedure are applicable. Although some nuclear staining was observed, using 5 to 6 minute hydrolysis and one-half hour staining, the results were not consistent. Nuclear detail was not apparent and a further disadvantage was the complete absence of staining of the ascus. The outline of the unstained ascus was so faint that finding the ascus (which was done under the high-dry objective) was difficult and even observations under oil immersion left some doubt as to its precise position.

Of the stains employed aceto-carmine and aceto-orcein were adopted for routine use in this study, because they gave by far the best results. Not only were they easy to use (requiring no preliminary treatments) but the chromosomes were also stained deeply and consistently. The most severe criticism of these stains is that various particles in the cytoplasm which are not nuclear may stain deeply. The only differences found between these stains were that carmine stained the cytoplasm more deeply than orcein and the former alone stained the nucleolus.

The cold treatment used was successful in producing a higher frequency of metaphase configurations but the chromosomes were so contracted that reliable counts were not possible. 


\section{GYTOLOGY OF SPECIES}

\section{Hypomyces solani (heterothallic)}

In this species a number of crosses were made most of which produced abundant perithecia. The observations made strongly suggest that the chromosome number is $n=5$ as can be seen in Figures 1 and 2 illustrating mitotic anaphase in ascospores. In each case 10 anaphase chromosomes appear to be present. This number is not in agreement with the findings of Hirsch (8) who, working with $\mathrm{H}$. Solani f. cucurbitae, reported $n=4$ in hermaphrodite, 3 in males and females and 2 in neuters or with $\mathrm{HI}$ Ani $(4,5)$ who found $n=4$ in all cases. In the latter paper $\mathrm{EI}$ Ani made a detailed study of the karyotype and concluded:

" Measurements of chromosome lengths at mid-pachytene were found to be $6.7: 4.5: 3.3: 1.5$ and the approximate ratio this would be $4.5: 3.0: 2,2: 1.0$. Chromosome 1 can be recognized by its large size and by its attachment to the nucleolus. One end of this chromosome is marked by a conspicuous heterochromatic segment that stains deeper than the other. Another heterochromatic region is located near the other end at which the nucleolus is attached... Chromosome 2 can be recognized by a distal and a proximal heterochromatic knob and chromosome 3 by its two heterochromatic distal ends. Chromosome 4 can be easily recognized because it is considerably smaller than the other chromosomes."

The photographs which BI Ani presents seem to bear out his conclusions quite fully and his analysis appears to have been quite detailed. However, in the present study several preparations were sufficiently clear (e.g. Figures 1 and 2) to leave little doubt that the chromosome number was $n=5$. Obviously further investigations are required

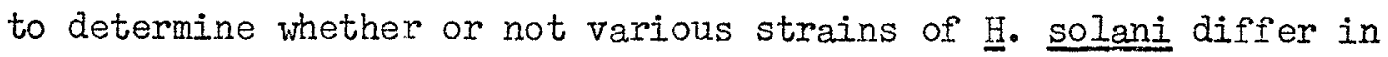


chromosome number as it would appear that more than one basic chromosome number exists in this species.

Hypomyces solani (homothallic)

The several strains used produced perithecia in large numbers. From the observations made it was concluded that the chromosome number for at least some homothallic strains for this species is also $\mathrm{n}=5$. In Figure 3 an ascus can be seen in which there appear to be 5 bivalents at metaphase I. This figure is typical of most of the preparations made in the study of the homothallic strains of this species. Some doubt as to the actual chromosome number still exists so that additional detailed studies should be conducted.

The first attempt to determine the chromosome number of this species was made by Hirsch (8) who concluded from observations on four different homothallic strains that the haploid number was six. The only other study of this species was made by EI Ani (6) who, on the basis of a limited number of observations, concluded that the number was $n=5$. The present study supports $E 1$ Ani's findings.

\section{Calonectria nivalis}

This is a homothallic species which produced perithecia readily when selfed. The number of observations on this species was limited but there appeared to be $n=7$ chromosomes. Figure 4 illustrates 7 bivalents at metaphase 1.

No previous cytological studies of this species have been made 
but Hirsch et al. (9) working with a closely related species, Calonectria rigidiuscula (Berk. et Br.) Sacc. (homothallic) found $\mathrm{n}=7$, but the photographic evidence demonstrating this chromosome number is not convincing.

\section{Gibberella zeae}

In this homothallic species two strains were used, and perithecia were produced readily. On the basis of a large number of observations there can be no doubt that this species has a chromosome number of $n=4$ (Figure 5). This number was previously found by Gordon (personal communication).

According to Snyder and Hansen (16) Gibberella zeae should actually be grouped, with a number of other species, into Gibberella roseum. Hirsch et ㄱ. . (8) claimed that in $\underline{G}$. roseum there are $n=6$ chromosomes, but the photographic evidence presented is vague. Since a haploid number of 4 appears to be characteristic of the genus Gibberella it must be assumed that the number reported by Hirsch is incorrect.

\section{Gibberella stilboides}

This is a heterothallic species in which only one cross, out of many, was satisfactory. On the basis of a number of observations, it was concluded that there are $n=4$ chromosomes (see Figure 6). No previous work has dealt precisely with this species but Hirsch et al. (8) postulated that $n=6$ in Gibberella lateritium and 
according to the classification of Snyder and Hansen (16) this species would include Gibberella stilboides. The photographic evidence submitted by Hirsch is far from conclusive and the present study leaves no doubt that four represents the true haploid number in $G$. stilboides.

\section{Gibberella fujikuroi}

In this species only one cross was used. On the basis of a number of observations it was concluded that $n=4$ (see figure 7).

No previous report on the number of chromosomes in this species was found in the literature.

\section{Gibberella cyanea}

This is a heterothallic species in which only one cross was used and the haploid chromosome number was conclusively shom to be $\mathrm{n}=4$ (Figure 8). In this figure a prophase III configuration is apparent in which the relative lengths of the chromosomes and some of the primary constrictions are visible. Although the chromosomes are too contracted for precise measuring the values obtained indicate approximately the relative lengths. These values were found to be 1.9: $1.3: 1.3:$ and 0.8 to the nearest tenth of a micron resulting in a ratio of $2.6: 1.8 \% 1.7: 1.0$ (using the original data).

No previous cytological study of this species has been found in the literature. 


\section{Gibberella cyanogena}

A large number of crosses were made in this heterothallic species and the resulting high fertility was conducive to intensive cytological study.

All the observations made on this species conclusively showed that there are $n=4$ chromosomes. This is an agreement with the earlier work of Gordon (personal communication) and EI Ani (4).

Figure 9 shows an ascus at prophase III in which the relative chromosome lengths in one of the nuclei are clearly visible and were found to be $2.2,1.9,1.6$ and 1.4 to the nearest tenth of a micron resulting in a ratio of $1.6 \% 1.4 \% 1.2: 1.0$.

Figure 10 also shows an ascus at prophase III in which the chromosomes of the most distinct nucleus have a length of $2.8,2.5$, 2.0 and 1.7 microns and thus a ratio of $1.7: 1.5: 1.2: 1.0$.

Figure 11 is a phase contrast photomicrograph of an ascus stained lightly with aceto-orcein, showing four bivalents in diakinesis of prophase 1. Although the lengths cannot be measured accurately at this stage it is obvious that the relative chromosome lengths are one long, two medium and one short.

Snyder and Hansen (16) reclassified G. cyanogena into the species G. roseum to which Hirsch et al. (9) ascribe a haploid chromosome number of six. The recent evidence including the present investigation casts much doubt on the validity of the earlier work of Hirsch et al. (9). 

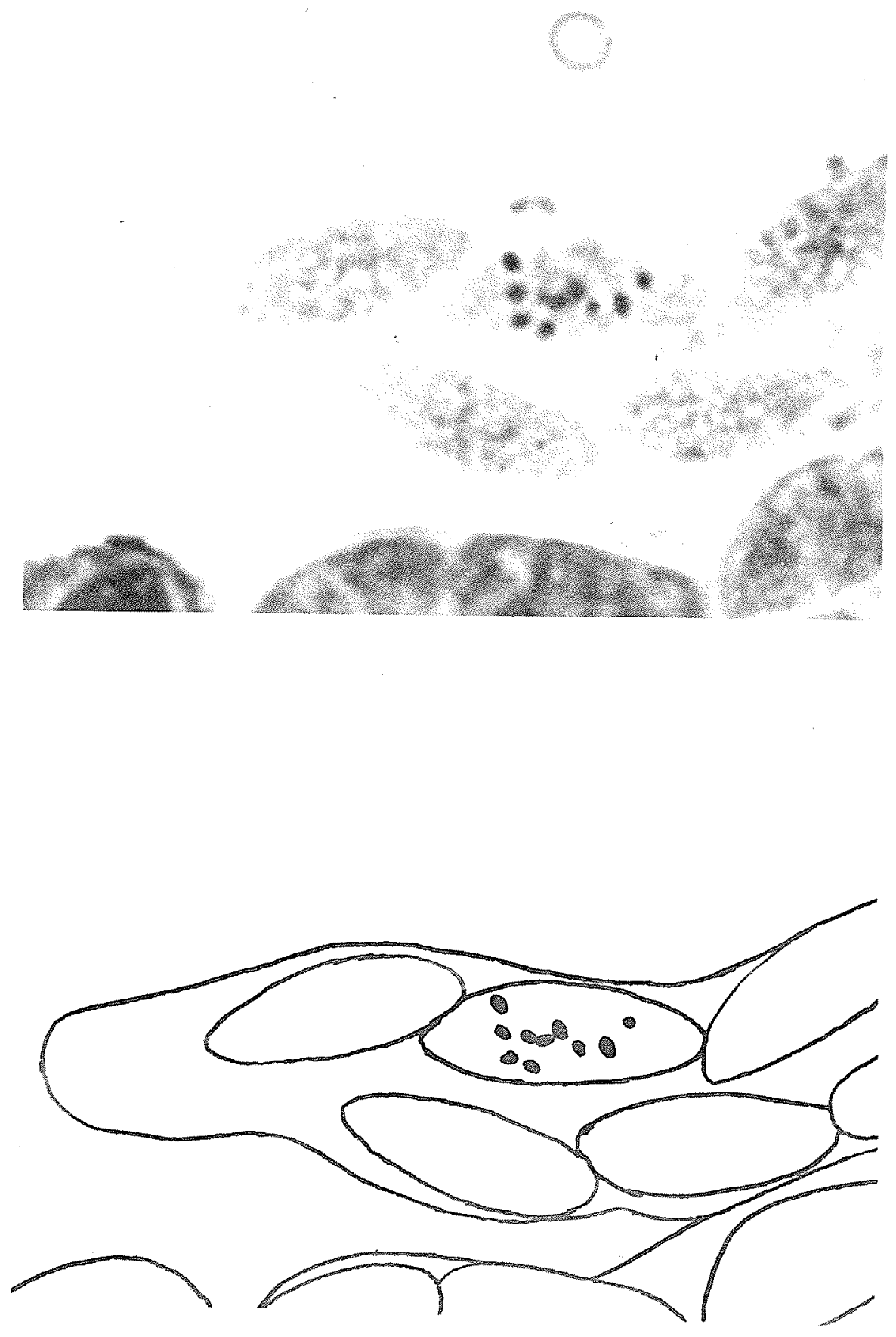

Figure 1. Hypomyces solani (heterothallic) showiug ter anaphase chromosomes in a young ascospore $(n=5)$. Acetomorcein $3000 \mathrm{X}$. 

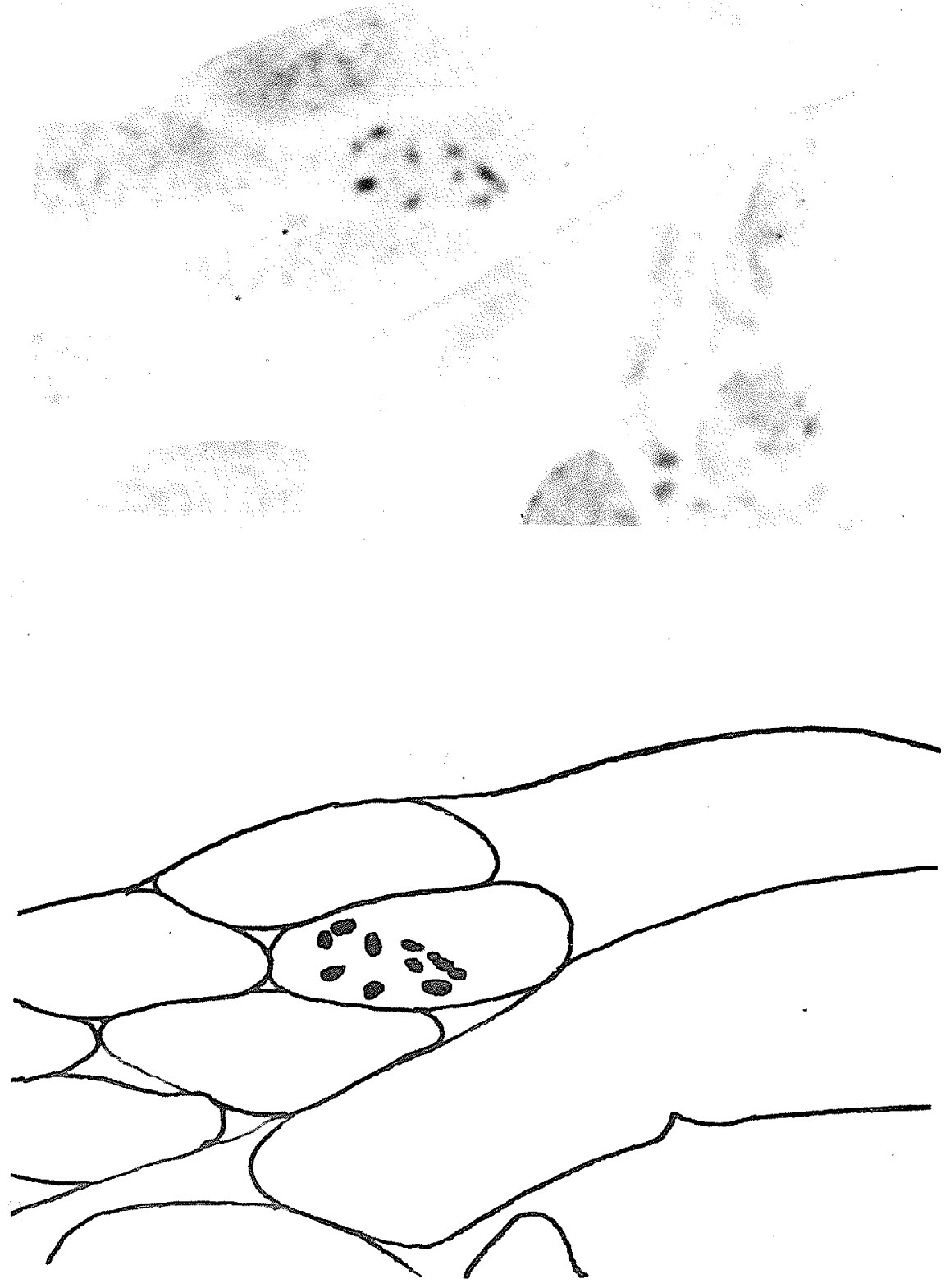

Figure 2. Hypomyces solani (heterothallic) showing ten anaphase chromosomes in mitosis of an ascospore $(n=5)$. Aceto
orcein $3000 \%$ 


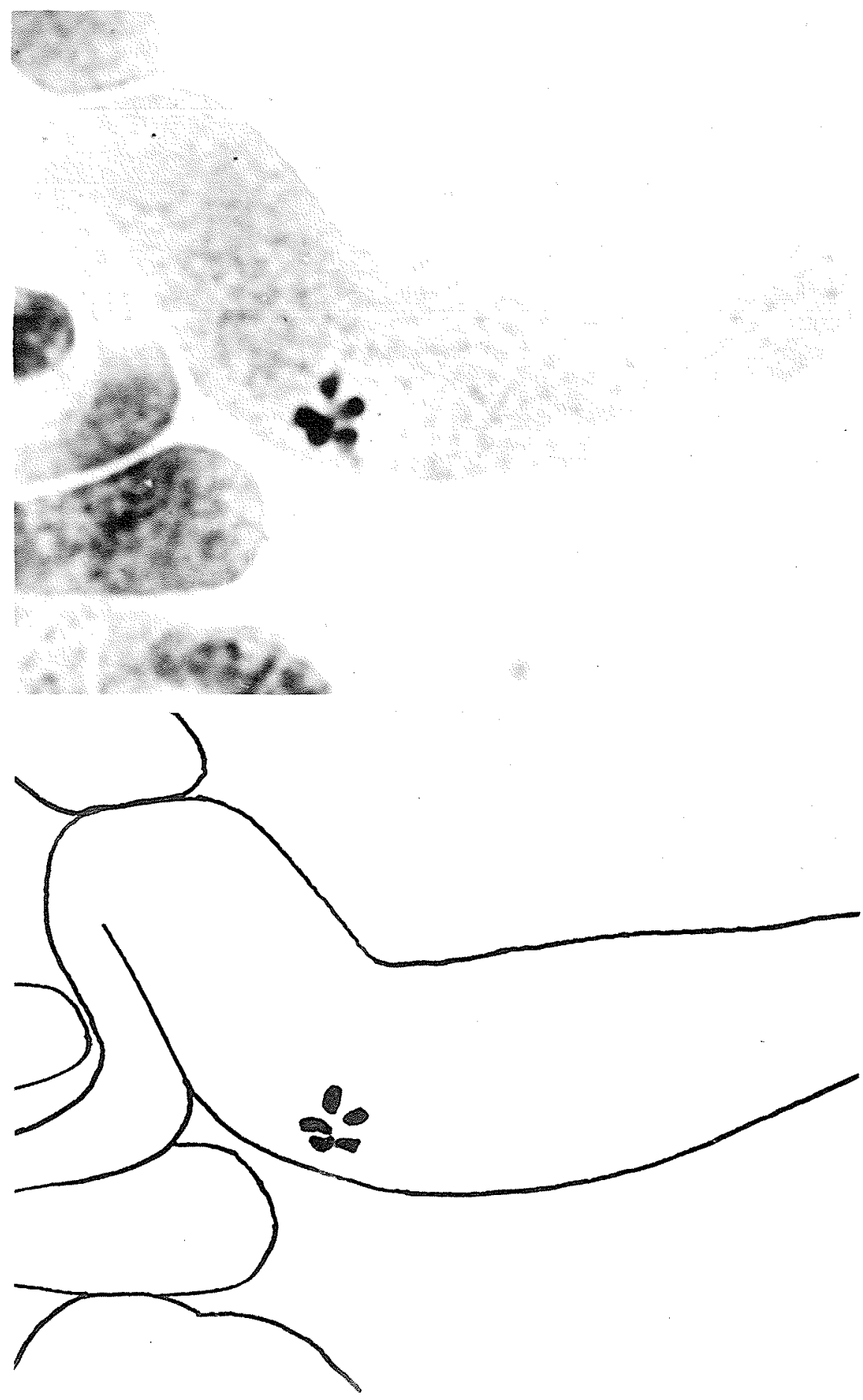

Figure 3. Hypomyces solani (homothallic) shozing five bivalents at metaphase I. Aceto-orcein 3000\% 

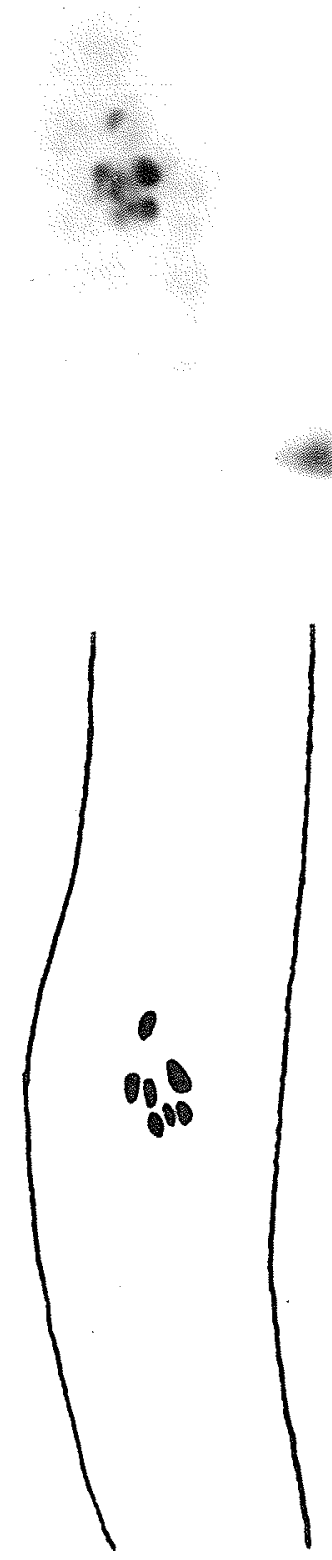

Figure 4* Calonectria nivalis shouing seven bivalents at metaphase I. Aceto-carmine $3000 \%$ 

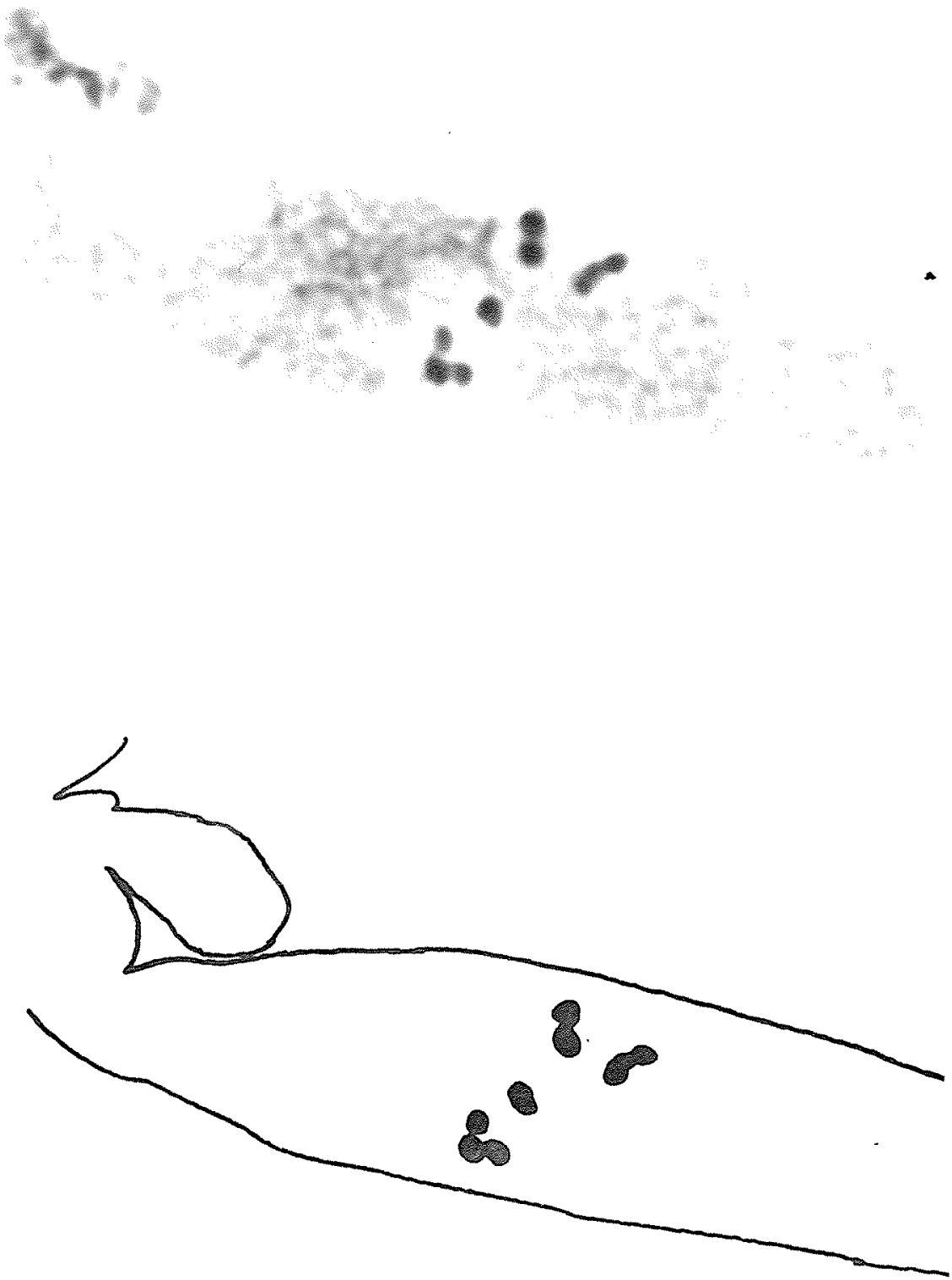

Nigure 5. Gibberella zeae showing four bivalents at metaphase I. Aceto-orcein 3000\%. 

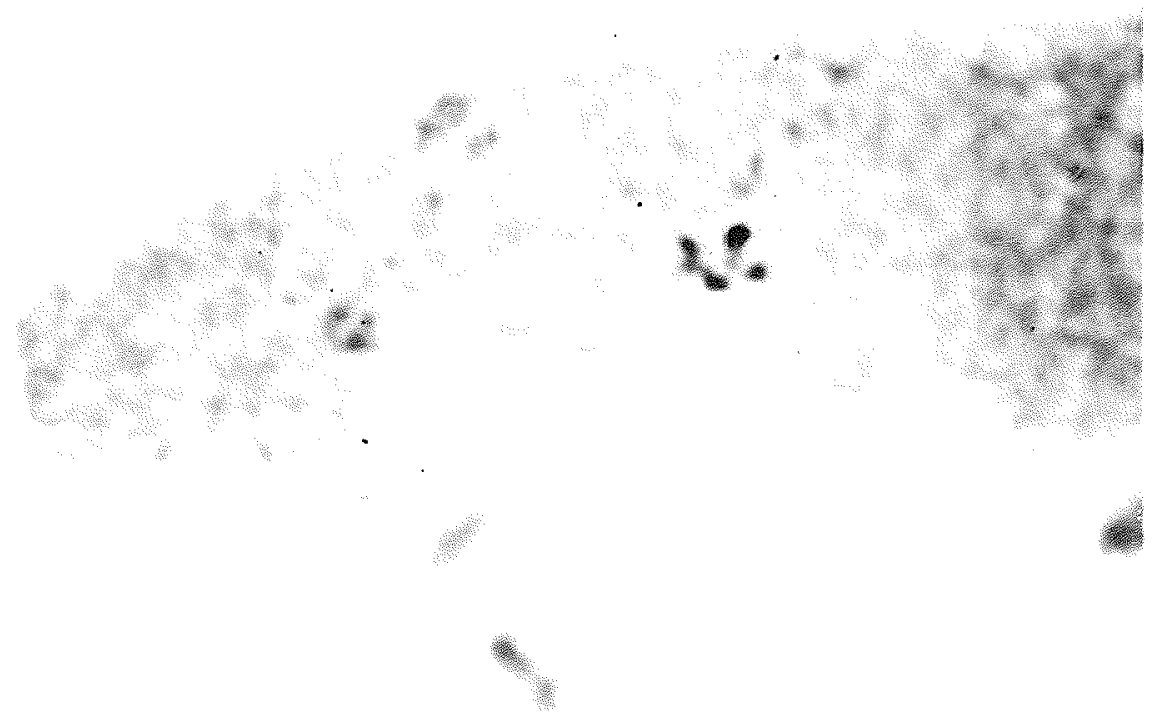

\%:
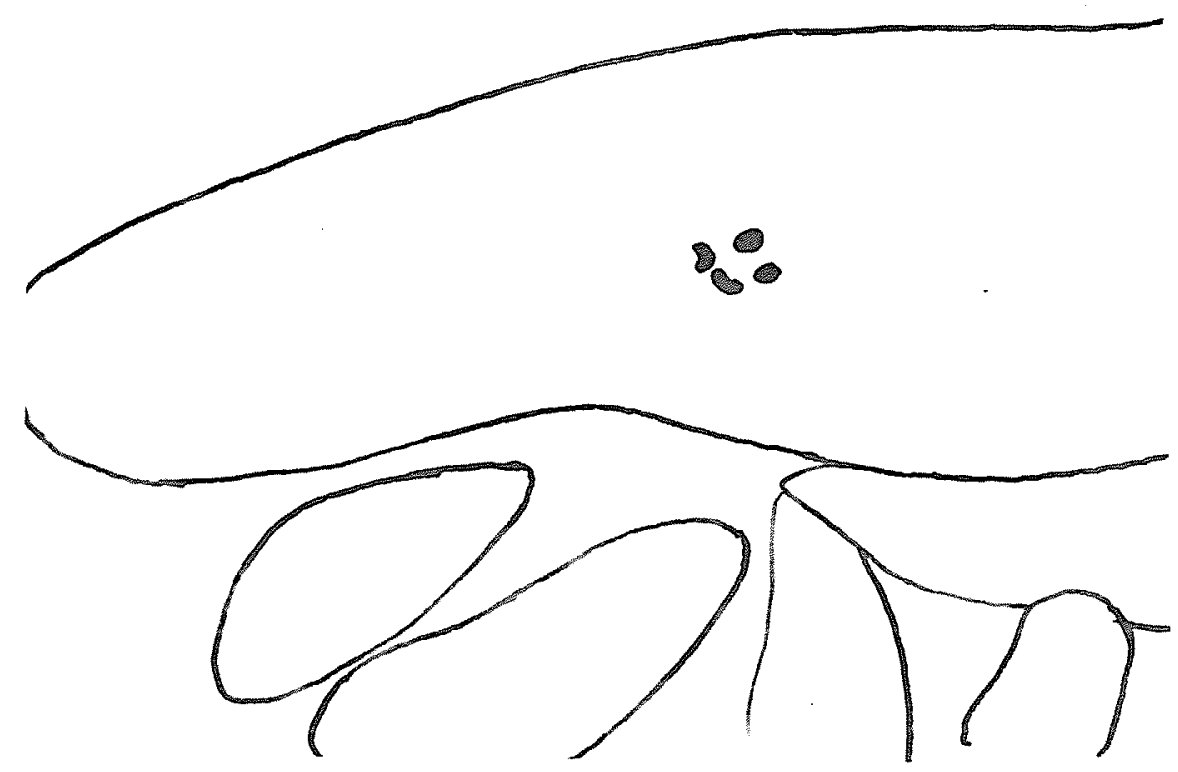

Figure 6. Gibberella stilboides with four bivalents at metaphase II. Aceto-orcein 3000X. 


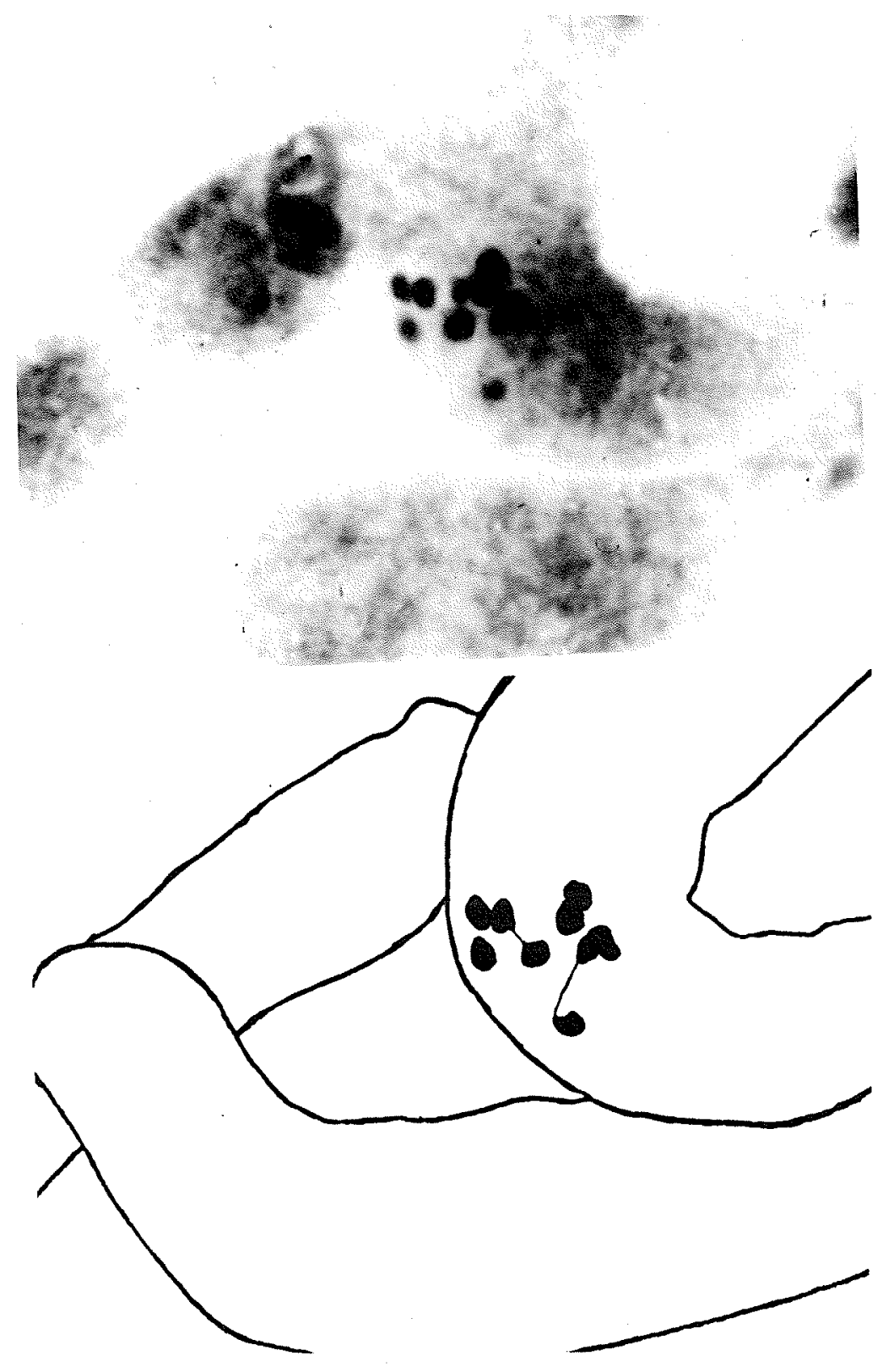

Figure 7. Gibberella fujikuroi at early anaphase I with four bivalents. Stained particle (omitted in drawing) is an artifact caused by deterioration of stored slide. Aceto-orcein $3000 x$. 

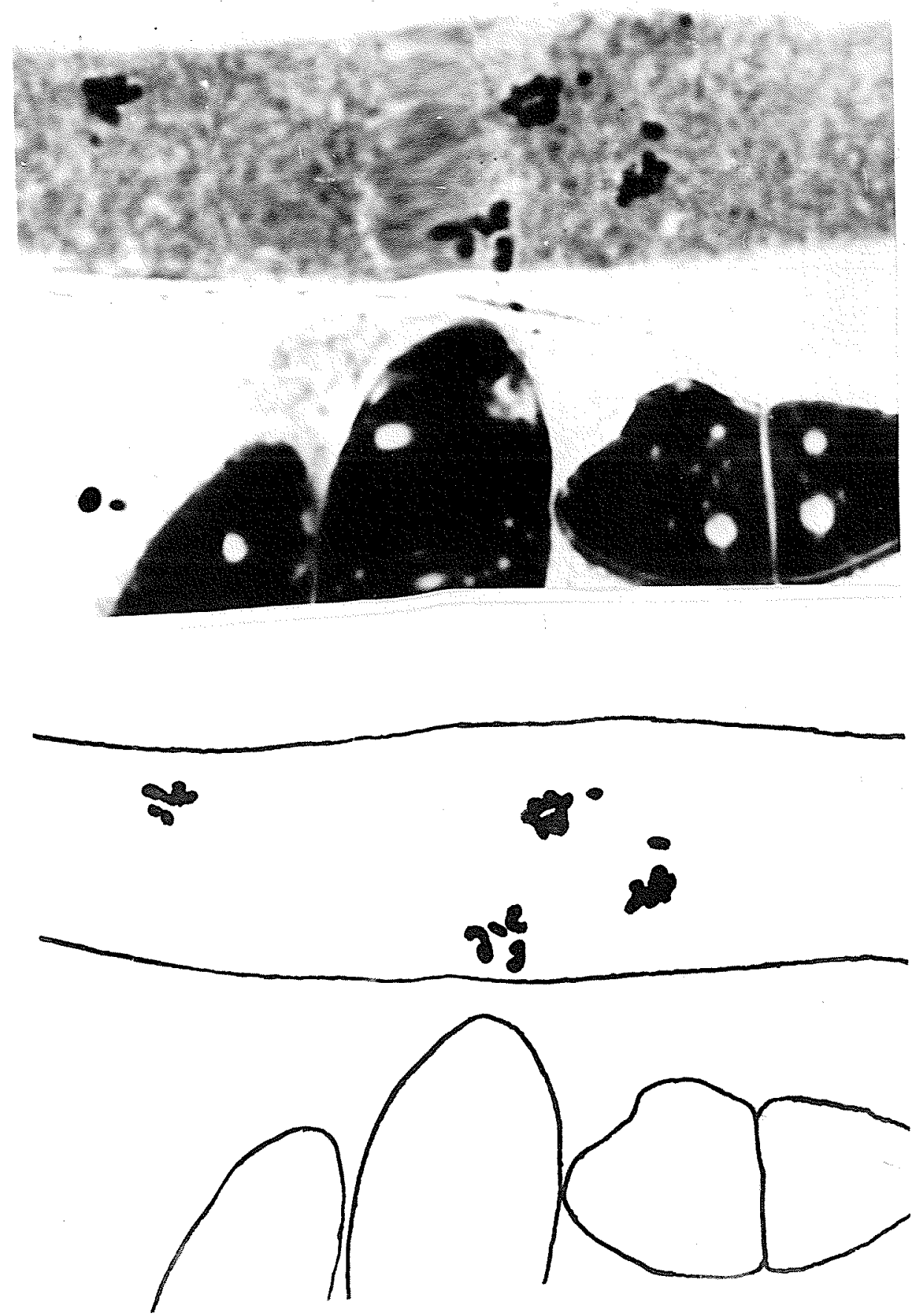

Figure 8. Gibberella cyanea, the 10wer middle nucleus at prophase III showing $n=4$ in which
made. Aceto-orcein $3000 \%$ 


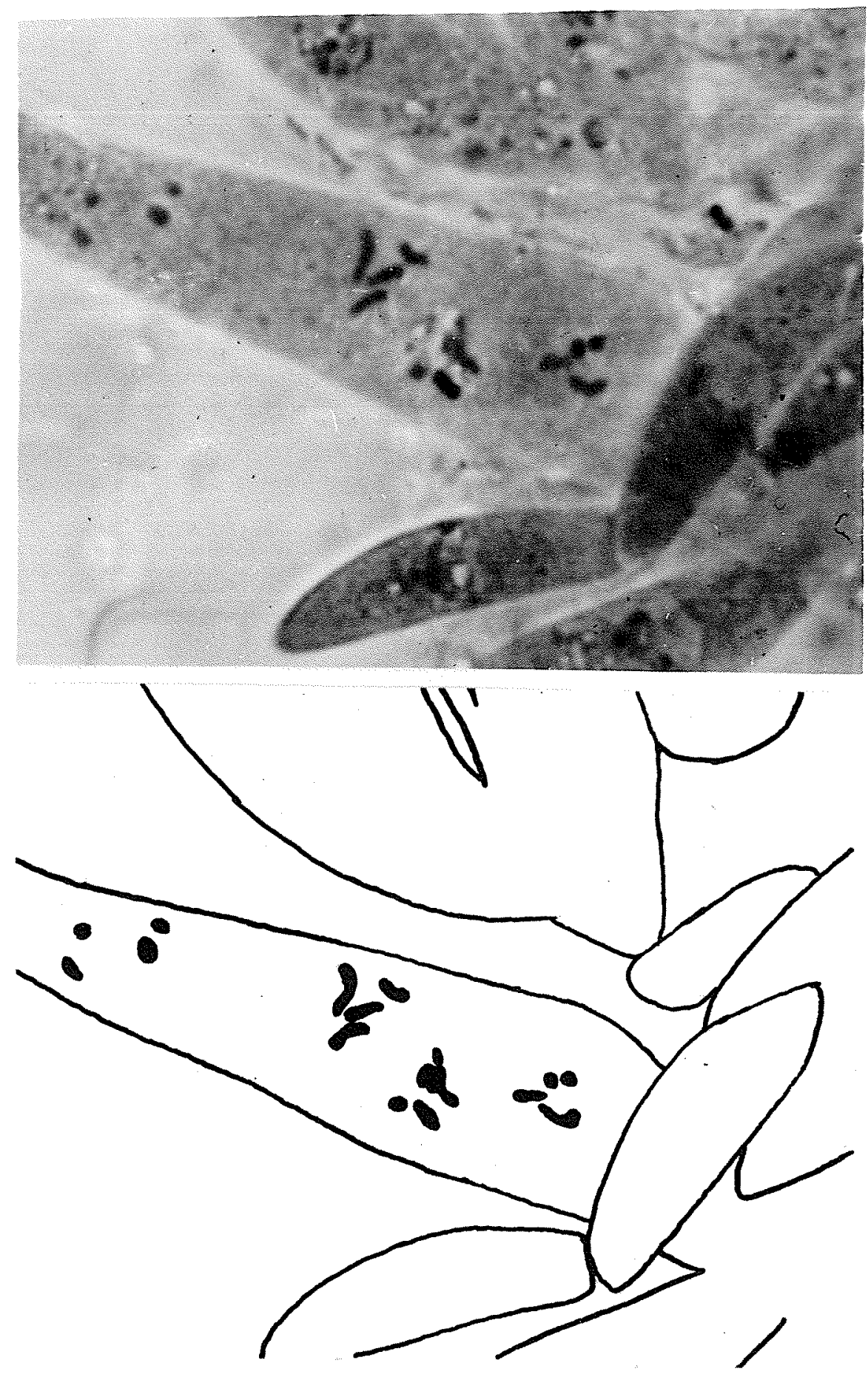

Figure 9. Gibberella cyanogena showing $n=4$ at prophase III. Chromosome lengths are distirct. Aceto-orcein $3000 \%$. 


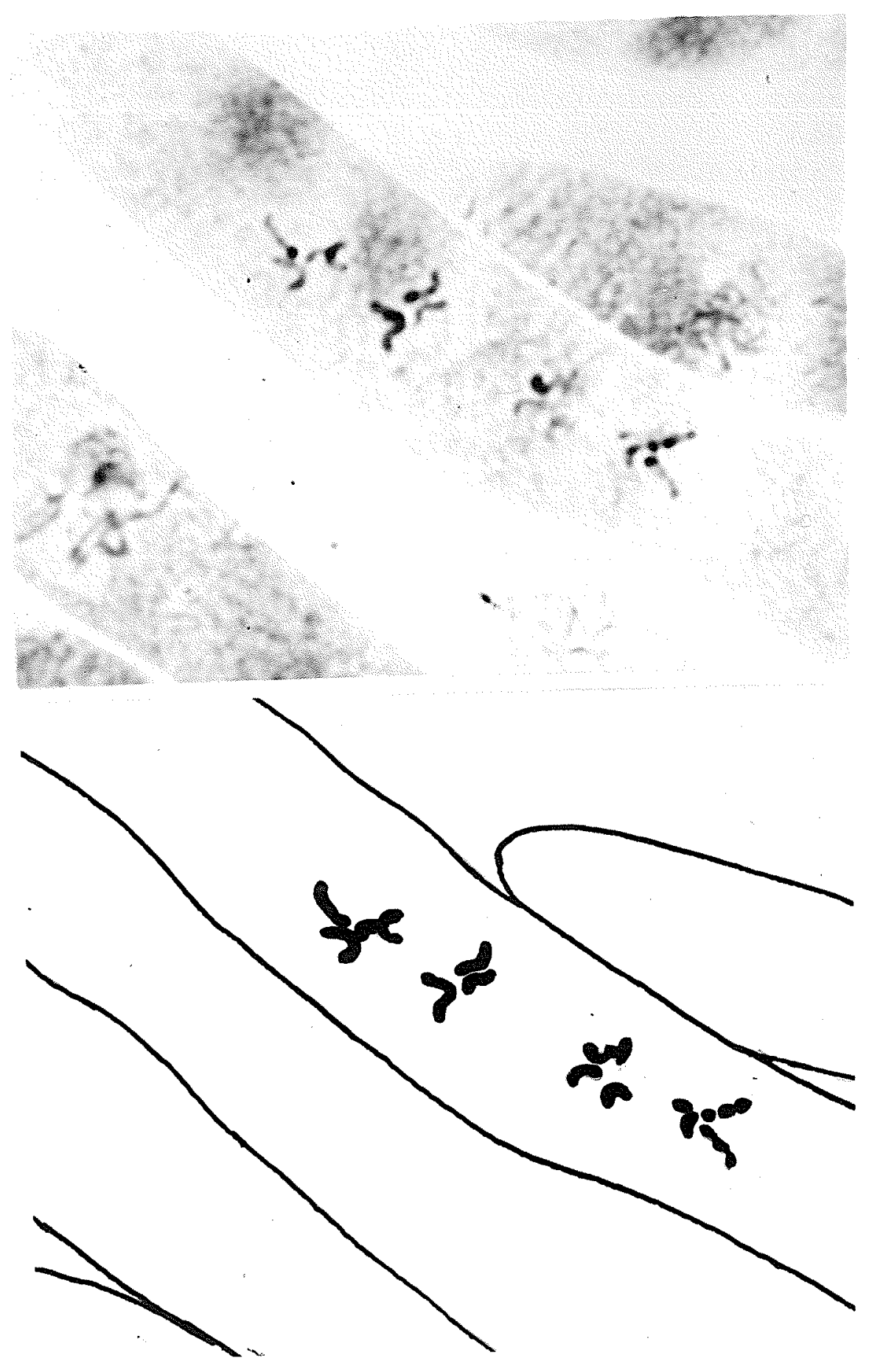

Figure 10. Gibberella cyanogena showing $n=4$ at prophase III, The chromosomes in the upper group were measured. Acetomorcein $3000 \mathrm{x}$. 

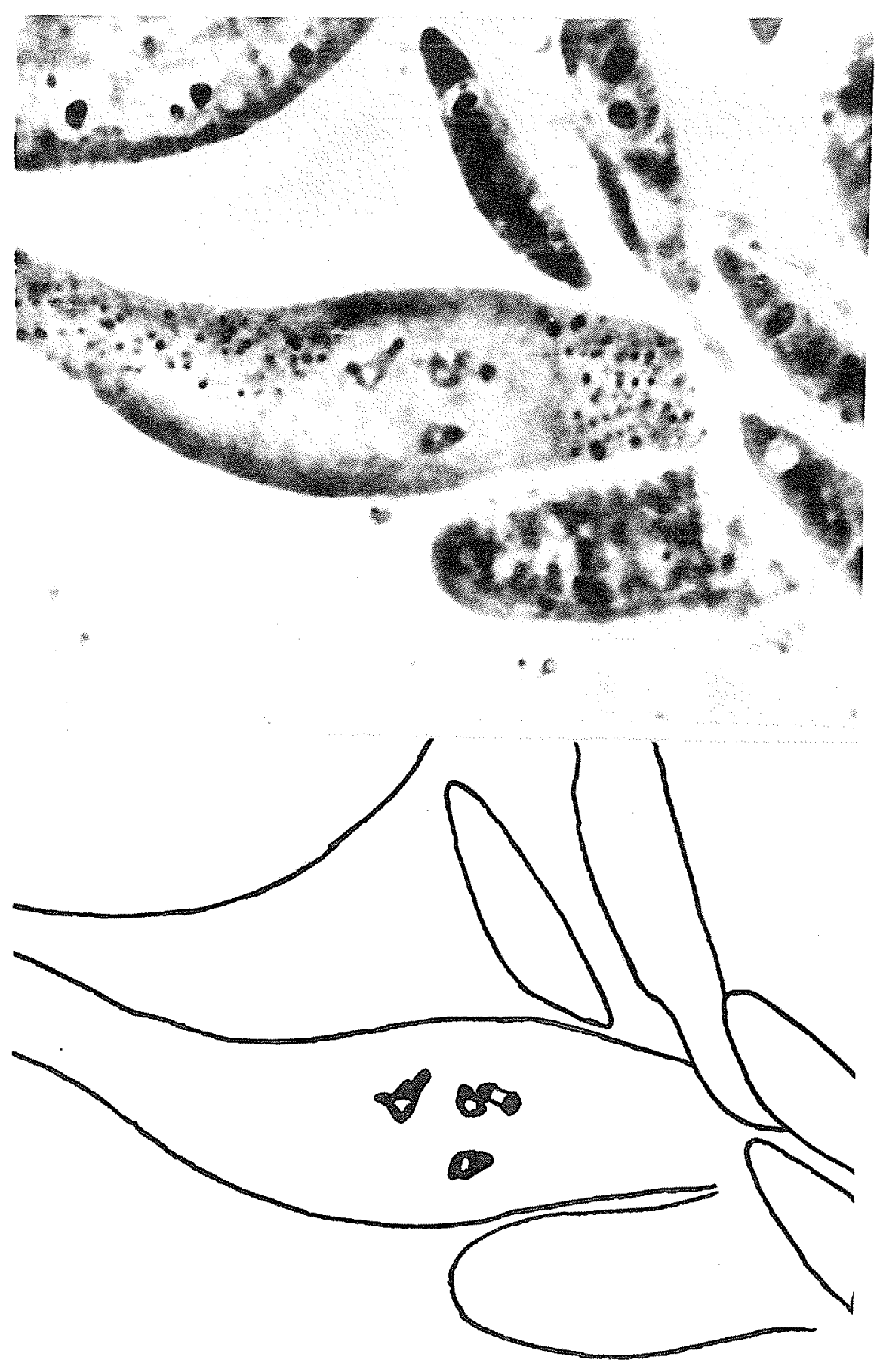

Figure 11. Gibberella cyanogena showing four bivalents at diakinesis. Phase contrast with aceto-orcein staining. 3000X. 


\section{GENEPAI DISCUSSION}

Sexual behaviour in some fungi has two components; sexual differentiation and compatibility. Sexual differentiation in higher organisms is usually determined by a heteromorphic pair of chromosomes and a similar condition may exist in some fungi.

The work of Hansen and Snyder (7) and EI Ani (2) showed that sexual differentiation in the heterothallic strain of $\mathrm{H}$. solani, designated $f$. cucurbitae, is dependent upon two linked loci (one determining maleness, the other, femaleness) and that a third locus, independent of the above two, determines the compatibility group. Each of these three loci has only one pair of alleles.

Hansen and Snyder (7) investigated the "dual phenomenon" in Hypomyces soleni and found two morphologically distinct types, $C$ (conidial) which can function as a hermaphrodite or a female and M(rnycelial) which can be male or neuter. It was found that $C$ types mutated consistently to $M$ types (although the reverse mutation was never observed) thus indicating the relative instability of sexual differentiation in this species. In Fusarium sambucinum $f .6$ the asexual stage of Gibberella cyanogena, EI Ani (4) observed the mutation of a hermaphrodite to a male strain which in crosses with a compatible hermaphrodite gave a ratio of $I$ hermaphrodite: 1 male. This suggests that the inheritance of sex in Gibberella is similar to that in Hypomyces. It appears therefore that sexual differentiation in these fungi, although profound in its manifestations, is simply inherited and has

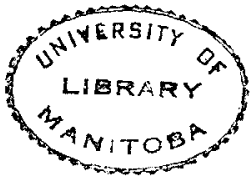


no particular relationship with chromosome number.

The phenomen of compatibility is much more obscure. Olive

(13) summed up compatibility as follows:

\begin{abstract}
"Physiological heterothallism (compatibility) is ... differentiated into bipolar and tetrapolar types, a single allelomorphic pair of factors controlling heterothallism in the bipolar types and two pairs controlling it in tetrapolar types. The bipolar type is found to characterize heterothallic fungi in the phycomycetes, ascomycetes, rust and smuts..."
\end{abstract}

The heterothallic species in this study had bipolar compatibility. Some elucidation of this problem has resulted from the work on Fuccinia by McGinnis (12) who found a relationship between sexual behaviour and the number of chromosomes. He concluded that "... the sexual behaviour may be dependent on chromosome number since all the homothallic species studied thus far (which consisted of four) have $n=4$ chromosomes while the heterothallic species (which totalled six) have either $n=3$ or $n=6$ chromosomes". It has been pointed out by the same author that the heterothallic species may constitute a polyploid series with a basic number of 3 .

Unfortunately the present work in $\underline{H}$. Solani has confused rather than elucidated the problem of homothallism and heterothallism. If the heterothallic has $n=4$ and the homothallic has $n=5$ as suggested by El ani (6) one could. surmise that the chromosome carrying the compatibility gene is present twice, each carrying a distinct opposite compatibility allele. However, in view of the present work which indicates that both strains have a common chromosome number such a hypothesis is unwarranted. 
It appears that homo- and heterothallic differences can occur between closely related species without obvious cytological changes. In the genus Gibberella one of the species studied (G. zeae) was homothallic and had $n=4$, as did the remainder of the species, all of which were heterothallic. It is possible that the homothallic species has a translocation bearing the opposite compatibility allele. One could also theorize that the compatibility locus might contain multiple alleles one or more of each conferring self-compatibility while only the two would determine self-incompatibility. If these hypothetical self-fertility alleles were incompatible with the recognized bipolar alleles, the former would never be recognized.

In all five species of Gibberella studied a haploid number of four was found, suggesting that this number is characteristic of the genus. The degree of homology between the chromosomes of each of these species was not determined except to note the qualitative similarity in chromosome lengths between $G$. cyanea and $G$. cyanogena. The measurement ratios made from both figures of $\underline{G}$. cyanogena are fairly consistent and could be relied upon with considerable confidence.

The minuteness of fungal chromosomes has necessitated observation tempered with a considerable degree of subjective interpretation, often resulting in contradictory reports on the number of chromosomes within a species. Late prophase and early anaphase were considered to be the most useful stages since in the former the chromosomes are relatively large and in the latter case separate chromosomes and bivalents are usually distinguishable. Metaphase is unreliable because in size alone 
at this stage a univalent is difficult to distinguish from a bivalent and disjunction of the chromosomes is often irregular.

There is some controversy in the literature over the type of nuclear division which occurs in fungi. In the present study no attempt was made to follow precisely the successive stages of nuclear division in the ascus but it is apparent that the figures shoun represent various stages in conventional nuclear division and consequently it is felt that meiosis and mitosis in the ascus is identical to that found in higher organisms. It is very likely that a similar type of nuclear division occurs also in the hyphae. 


\section{CONCLUSIONSS}

Of the variety of stains used aceto-orcein and aceto-carmine gave the best results.

The present limiting factor in chromosome studies in the Ascomycetes is primarily the inadequate resolution of the light microscope. At many stages the chromosomes are reduced to a size approaching the absolute limit of resolution of the light microscope. Although the haploid number of chromosomes varied considerably in the species studied, seven in Calonectria nivalis, five in Hypomyces solani and four in the genus Gibberella, the asexual stage of each species is included in the form-genus Fusarium. From this it could be inferred that the chromosome differences represent a basic genotypic differential which is expressed primarily in the morphology of the sexual sta.ge.

The characteristic chromosome complement of Gibberella is comprised of one long, two medium and one short chromosome.

In the one species studied where homo- and heterothallic strains were present no association between this phenomenon and chromosome number was found.

From the observations made in this study it appears that nuclear division in fungi is similar to that found in higher organisms. 
REFERENCES

1. CONGER, A.D. AND FAIRCHIID, L.M. 1953. A quick-freeze method for making smear slides permanent. Stain Technol. 28: $281-283$

2. EL ANI, ARIF S. 1954. The genetics of sex in Hypomyces solani f. cucurbitae. Am. J. Botany 4I(2): 110-113.

3. 1954. Chromosomes of Hypomyces solani f. cucurbitae. Science 120: 323-324.

4. 1956. Cytogenetics of sex in Gibberella cyanogena (DESM) SACC. Science 123: 850.

5. 1956. Ascus development and nuclear behaviour in Hypomyces solani f. cucurbitae. Am. J. Botany 43 (10): 769.

6. 1959. Chromosome numbers in the Hypocreales $I$. Nuclear divisions in the ascus of Nectria peziza. Am. J. Botany 46 (b): 412-417.

7. HANSEN, H.N. AND SNYDER, W.C. 1943. The dual phenomenon of sex in Hypomyces solani f. cucurbitae. Am. J. Botany 30: 419-422.

8. HIRSCH, H.E. 1949. The cytogenetics of sex in Hypomyces solani f. cucurbitae. Am. J. Botany 36: 113-121.

9. HIRSCH, H.E., SNYDER, H.C. AND HANSEN, H.N. 1949. Chromosome numbers in the Hypocreaceae. Mycologia 41: 411-415. 
10. HRUSHOVETZ, S.B. 1956. Cytological studies of ascus development in Cochliobolus sativus. Can. J. Botany 34: 641-651.

11. McCLINTOCK, B. 1945. Neurospora I. Preliminary observations of the chromosomes of Neurospora crassa. Am. J. Botany $32: 671-678$.

12. McGIMIIS, R.C. 1956. Cytological studies of chromosomes in rust fungi. III. The relationship of chromosome number to sexuality in Puccinia. Jour. Heredity 47: 255-259.

13. OLIVE, L.S. 1953. The structure and behaviour of fungus nuclei. Bot. Revue 19: 439-586.

14. RAPER, J.R. 1959. Sexual versatility and evolutionary processes in fungi. Nycologia 51: 107-124.

15. SINGLETON, J.R. 1953. Chromosome morphology and the chromosome cycle in the ascus of Neurospora. Am. J. Botany 40 : $124-144$.

16. SNYDER, H.C. AND HANSON, H.N. 1945. The species concept in Fusarium with reference to discolor and other sections. Am. J. Botany 32: 657-666。

17. TSUNEWAKI, K. AND JENKINS, B.C. 1960. A comparative study of various methods of root-tip preparation in screening wheat aneuploids. Cytologia 25: 373-380.

18. WOLLENWEBER, H.W., AND REINKING, O.A. 1935. Die Fusarien, ihre Beschreibung, Schadwirkung und Bekampfung. PauI Parey, Berlin. 